\title{
Asymptomatic Plaque on the Scalp
}

Fernando García-Souto, MD; Isabel María Coronel-Pérez, MD; Yessica Sánchez-Santos, MD;

Jerónimo Escudero-Ordoñez, MD, PhD

Eligible for 1 MOC SA Credit From the ABD

This Photo Challenge in our print edition is eligible for 1 self-assessment credit for Maintenance of Certification from the American Board of Dermatology (ABD). After completing this activity, diplomates can visit the ABD website (http://www.abderm.org) to self-report the credits under the activity title "Cutis Photo Challenge." You may report the credit after each activity is completed or after accumulating multiple credits.

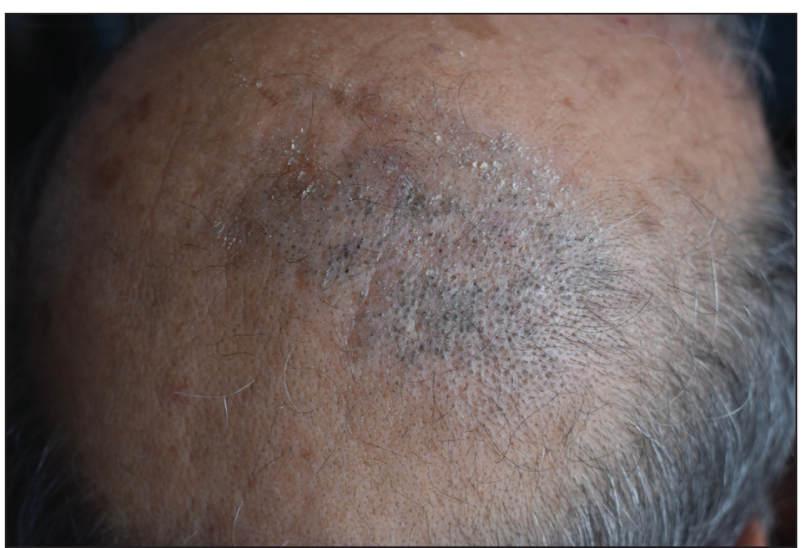

A 50-year-old man presented to the dermatology department with an asymptomatic plaque on the scalp that had been present since childhood. The size of the plaque gradually progressed initially but had notably increased in size in the last 6 months. There was no association with trauma or irritation. There was no family history of similar lesions. Physical examination revealed a $3.0 \times 2.5-\mathrm{cm}$ plaque on the vertex of the scalp consisting of aggregated pits plugged with keratinous material resembling comedones. There were no lesions elsewhere on the body. Dermoscopy and a 4-mm punch biopsy were performed.

\section{WHAT'S THE DIAGNOSIS?}
a. familial dyskeratotic comedones
b. folliculotropic mycosis fungoides
c. nevus comedonicus
d. porokeratotic eccrine ostial and dermal duct nevus
e. seborrheic keratosis

\footnotetext{
From Valme University Hospital, Avenida Bellavista, Seville, Spain. Drs. García-Souto, Coronel-Pérez, and Escudero-Ordoñez are from the Department of Dermatology, and Dr. Sánchez-Santos is from the Department of Pathology. 


\section{THE DIAGNOSIS: Nevus Comedonicus}

$\square$ ermoscopy showed multiple dilated follicular openings plugged with keratinous material (Figure 1). Histopathology revealed dilated follicular infundibula with dilation and orthokeratotic plugging (Figure 2). Routine laboratory tests including complete blood cell count and blood chemistry were within reference range. Thus, on the basis of clinical, dermoscopy, and histopathological findings, a diagnosis of nevus comedonicus (NC) was made. The patient refused treatment for cosmetic reasons.

Nevus comedonicus is a rare hamartoma first described by Kofmann ${ }^{1}$ in 1895 . It is thought to be a developmental defect of the pilosebaceous unit; the resulting structure is unable to produce mature hairs, matrix cells, or sebaceous glands and is capable only of forming soft keratin. ${ }^{2}$ Clinically, it is characterized by closely grouped papules with hyperkeratotic plugs that mimic comedones. It has a predilection for the face, neck, and trunk area. Nevertheless, scalp involvement rarely has been reported in the literature. ${ }^{2-4}$ Nevus comedonicus usually appears at birth or during childhood and generally is asymptomatic; however, an inflammatory variant of NC with cyst formation and recurrent infections also has been described. ${ }^{5}$ Moreover, a syndromic variant was reported and characterized by a combination of NC with ocular, skeletal, or neurological defects. ${ }^{5}$ Most lesions grow proportionately with age and usually stabilize by late adolescence. ${ }^{2}$ Our patient's plaque increased in size with age. No triggering factors were found. Although NC usually has a benign course, squamous cell carcinoma arising in NC has been reported. ${ }^{6}$ Consequently, routine surveillance is necessary.

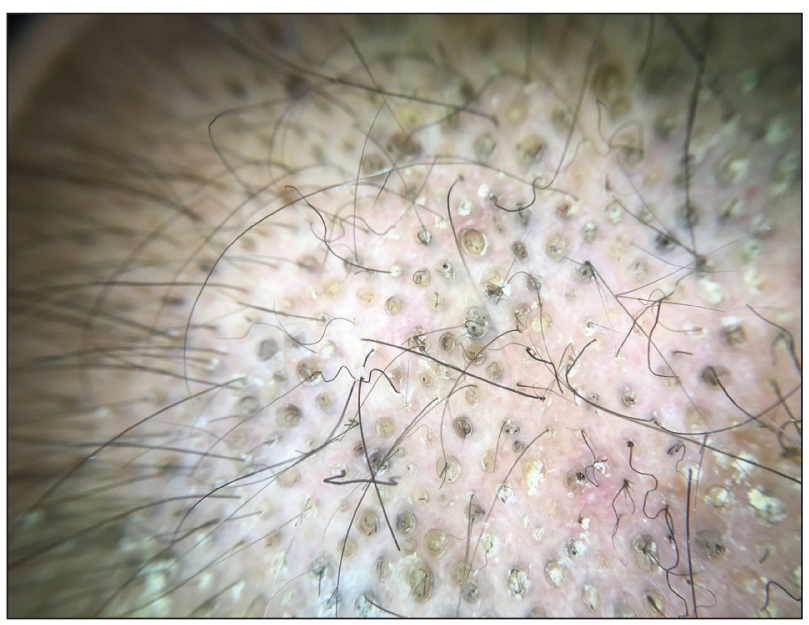

FIGURE 1. Dermoscopy showed multiple dilated follicular openings plugged with keratinous material.

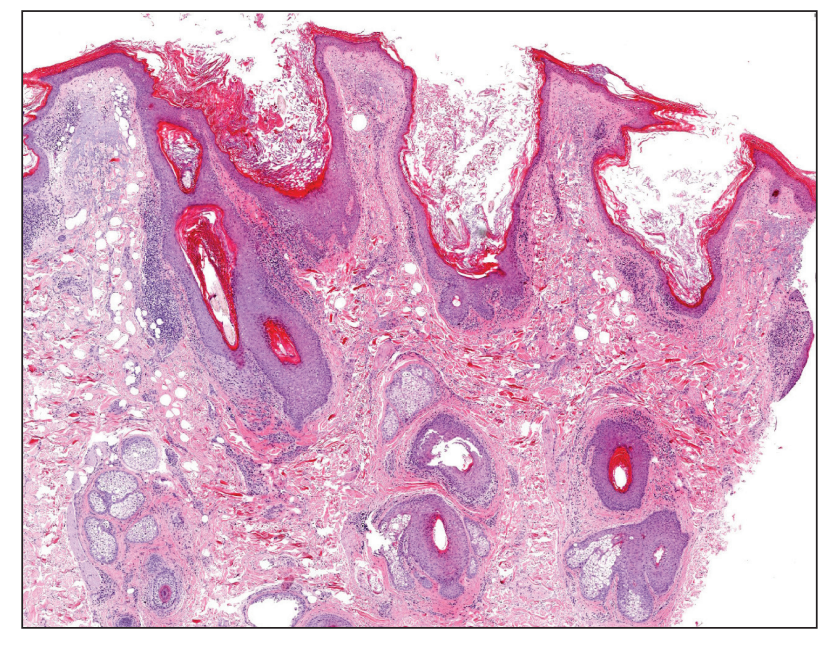

FIGURE 2. Histopathology showed dilated follicles with corneal orthokeratotic material and an atrophic epithelium (H\&E, original magnification $\times 20)$.

Diagnosis often is easily made by considering the characteristic morphology of the lesions and the early age of its appearance. However, in atypical NC presentations, acne, seborrheic keratosis, porokeratotic eccrine ostial and dermal duct nevus, folliculotropic mycosis fungoides, Favre-Racouchot syndrome, or familial dyskeratotic comedones should be considered. Dermoscopy has been reported to be useful in the diagnosis of NC. Typical dermoscopy findings are numerous circular and barrel-shaped homogenous areas in light and dark brown shades with remarkable keratin plugs. ${ }^{7,8}$

Folliculotropic mycosis fungoides is a variant of mycosis fungoides characterized by hair follicle invasion of mature, $\mathrm{CD}^{+}$, small, lymphoid cells with cerebriform nuclei. ${ }^{9}$ Patients may present with grouped follicular papules that preferentially involve the head and neck area. It typically occurs in adults but occasionally may affect children. Histopathology is characterized by the presence of folliculotropic infiltrates with variable infiltration of the follicular epithelium, often with sparing of the epidermis. Familial dyskeratotic comedones, rare autosomal-dominant genodermatoses, clinically are characterized by symmetrically scattered comedonelike hyperkeratotic papules. These lesions appear around puberty and show a predilection for the trunk, arms, and face. Histopathology reveals craterlike invaginations filled with keratinous material and evidence of dyskeratosis. Porokeratotic eccrine ostial and dermal duct nevus is a rare adnexal hamartoma with eccrine differentiation. It is characterized by asymptomatic grouped keratotic papules and plaques. The lesions usually present at birth or in childhood and favor the palms and soles. Widespread 
involvement along Blaschko lines also can occur. Cornoid lamella involving an eccrine duct is the characteristic histopathologic feature of this condition. ${ }^{9}$

Treatment of NC is essentially reserved for cosmetic reasons or when there are complications such as discomfort or infection. Treatment options include topical corticosteroids, topical retinoids, and keratolytic agents such as ammonium lactate or salicylic acid. ${ }^{10}$ The use of oral isotretinoin is controversial. ${ }^{2}$ Surgical excision is useful for localized lesions. Nevus comedonicus, especially occurring at unusual sites such as the scalp, is uncommon. Therefore, a high index of suspicion is required to reach a diagnosis.

\section{REFERENCES}

1. Kofmann S. Ein fall von seltener localisation und verbreitiing von comedonen. Arch Derm Syph. 1895;32:177-178.
2. Sikorski D, Parker J, Shwayder T. A boy with an unusual scalp birthmark. Int J Dermatol. 2011;50:670-672.

3. Ghaninezhad H, Ehsani AH, Mansoori P, et al. Naevus comedonicus of the scalp. J Eur Acad Dermatol Venereol. 2006;20:184-185.

4. Kikkeri N, Priyanka R, Parshawanath H. Nevus comedonicus on scalp: a rare site. Indian J Dermatol. 2015;60:105.

5. Happle R. The group of epidermal nevus syndromes. J Am Acad Dermatol. 2010;63:1-22

6. Walling HW, Swick BL. Squamous cell carcinoma arising in nevus comedonicus. Dermatol Surg. 2009;35:144-146.

7. Kamińska-Winciorek G, Śpiewak R. Dermoscopy on nevus comedonicus: a case report and review of the literature. Postepy Dermatol Alergol. 2013;30:252-254

8. Vora R, Kota R, Sheth N. Dermoscopy of nevus comedonicus. Indian Dermatol Online J. 2017;8:388.

9. Wang NS, Meola T, Orlow SJ, et al. Porokeratotic eccrine ostial and dermal duct nevus: a report of 2 cases and review of the literature. Am J Dermatopathol. 2009;31:582-586.

10. Ferrari B, Taliercio V, Restrepo P, et al. Nevus comedonicus: a case series. Pediatr Dermatol. 2015;32:216-219 